\title{
Experimental Evaluation on Mixed Mode I/II Stress Intensity Factors using CTS welded and non-welded specimen of Aluminum Alloy AA3003
}

\author{
Hichem Mebarki ${ }^{1}$, Abdelkader Lahcene ${ }^{2}$, Mohamed Benguediab ${ }^{3}$,Hamida Fekirini ${ }^{4}$ \\ ${ }^{1}$ Laboratory of Materials and Reactive Systems -University DjillaliLiabes of SidiBel Abbes, Algeria, \\ 1993hicham76@gmail.com \\ ${ }^{2}$ Laboratory of Materials and Reactive Systems -University DjillaliLiabes of SidiBel Abbes, Algeria, \\ lhkader@yahoo.fr \\ ${ }^{3}$ Laboratory of Materials and Reactive Systems -University DjillaliLiabes of SidiBel Abbes, Algeria, \\ benguediabm@gmail.com \\ ${ }^{4}$ Laboratory of Mechanics and Physical Materials -University DjillaliLiabes of SidiBel Abbes, Algeria, \\ fekirini.hamida@gmail.com
}

Received Date : August 04, 2021 Accepted Date : August 23, 2021 Published Date : September 07, 2021

\begin{abstract}
In the present paper, experimental investigation on the fracture of aluminum alloy AA3003 are conducted on the Compact Tension Shear CTS specimen non-welded and CTS specimen welded by FSW process under mixed mode loading by using Arcan loading device based on Richard's principle suitable for mixed mode. All loading in mixed mode starting from pure tension (mode I) up to pure shear (mode II) can be obtained and tested by varying the loading angles from $0^{\circ}$ to $90^{\circ}$. The stress intensity factor for the Compact Tension Shear (CTS) specimen are determined three normalized lengths cracks $0.3,0.5$ and 0.7 . The length of notches influence on the variation of stress intensity factor $\mathrm{K}_{\mathrm{I}}, \mathrm{K}_{\mathrm{II}}$. For CTS specimen with notches with a short length, the values of $\mathrm{K}_{\mathrm{II}}$ are greater than those obtained for notches with a long length.
\end{abstract}

Key words: Mixed-mode loading, CTS specimen, Friction stir welding, Stresses intensity factors mode I, mode II.

\section{INTRODUCTION}

Lightening structures is one of the major challenges of the aeronautics industry. At a time when composite materials are becoming increasingly important in structures, the use aluminum alloy assembled by Friction Stir Welding (FSW) is being considered to replace riveted structures in traditional aluminum alloys in many industrial sectors such as aeronautics, automotive industry etc. FSW welding is particularly interesting for the assembly of aluminum alloys used in the aviation industry [1] which, until then, were of little use due to their instability with traditional welding processes. The use of FSW welds on the airfoils to replace rivets allows a gain of $20 \%$ in total airfoil mass. In today's environment, FSW friction stir welding has the advantage of being fast, economical and suitable for welding aluminum alloys used in metal assemblies. However, although this FSW welding process has definite advantages in terms of saving mass, defects canbe generated by heating and mixing of the material. The presence of these defects is the main cause of sudden ruptures leading to catastrophic situations [2]. The consideration of these defects and the risk of breakage is an important issue in the design of mechanical components; therefore the operation of welded structures by FSW requires knowledge of the behavior of the material and its long-term behavior. Numerous research works [3]-[8] have been carried out to define the behavior of joints welded by FSW, in particular in quasi-static traction and fatigue. To characterize the behavior in fracture of the material, the various types of loading are often idealized as being the pure mode I and the pure mode II used as the solutions of the elastic linear mechanics of the fracture. However, structures undergo complex loadings under service conditions involving a combination of tension (mode I), in-plane shear (mode II) and sometimes out-of-plane shear (mode III), these combinations of failure mode are called mixed mode of rupture. Several studies on the fatigue behavior of materials in mixed mode have been carried out [9]-[13].

The specimens used for mixed mode I/II tests are not standardized, several types of specimens have been proposed. The specimens who are widely used for the loading in mixed mode I / II, are those developed by Richard [14] called Compact Tension shear (CTS).This geometry is widely used to study fracture toughness and fatigue crack growth [15]-[19].The behavior fracture in mode I, mode II and in mixed mode on welded specimens of aluminum alloys has been the subject of several studies. However, few studies have 
focused on the mixed fracture behavior of aluminum alloys welded by FSW using compact shear specimens (CTS). Richard et al. [20] determined the stress intensity factors in $\mathrm{K}_{\mathrm{I}}$ and $\mathrm{K}_{\mathrm{II}}$ for the pre-cracked specimen CTS by assuming that the crack remains plane and normal to the lateral faces. Antunes et al. [21] determined empirically the stress intensity factors $\mathrm{K}_{\mathrm{I}}, \mathrm{K}_{\mathrm{II}}$ for in mixed mode with CTS specimens, taking into account the variation the length of the crack, the angle of loading and the orientation of the crack.In recent work, $\mathrm{Al}$ Emran [22] presents the solution of modes I, II and III stress intensity factors (SIFs) for surface cracks in round solid bars using ANSYS WORKBENCH finite element analysis.

In the present paper, experimental investigation on the fracture of aluminum alloy AA 3003 specimens welded by FSW process and specimens non welded is studied in mixed mode by using a CTS specimen.

\section{EXPERIMENTAL METHOD}

\subsection{Material study}

This study was conducted on the wrought Aluminum Alloy AA3003 of the aluminum-manganese family using Compact Tension Shear welded and non-welded specimens with thickness $\mathrm{B}=2 \mathrm{~mm}$, Width $\mathrm{W}=60 \mathrm{~mm}$. All the test specimens were notched using water jet cutting. Three different crack normalized lengths were tested, $\mathrm{a} / \mathrm{W}=0.3,0.5$ and 0.7 .

The chemical composition and mechanical properties of the material were determined by Chekalil et al. [23] and reported in tables 1 .Figure 1 shows stress-strain curve of the material before welding

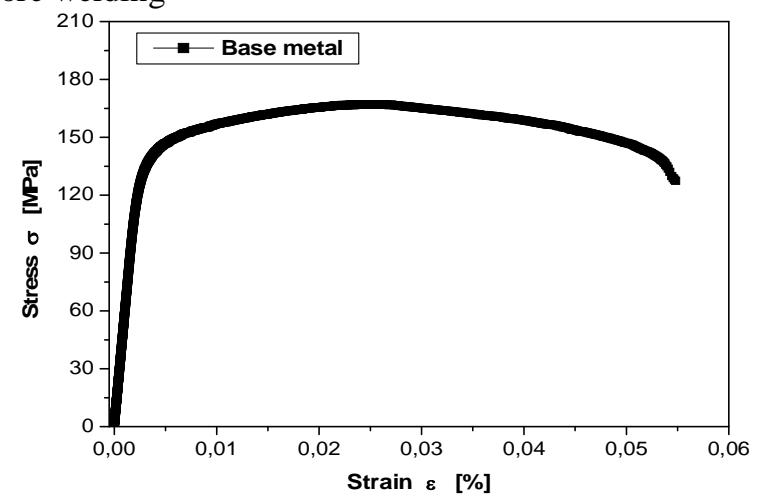

Figure 1: Stress-strain curve of the material before welding[23].

Table 1:Chemical composition of the material[22].

\begin{tabular}{|c|l|c|c|l|l|l|l|}
\hline Element & $\mathbf{A l}$ & $\mathbf{M n}$ & $\mathbf{S i}$ & $\mathbf{F e}$ & $\mathbf{C u}$ & $\mathbf{T i}$ & $\mathbf{Z n}$ \\
\hline$\%$ & 96.7 & 1.3 & 0.9 & 0.13 & 0.13 & 0.1 & 0.03 \\
\hline
\end{tabular}

Mechanical properties of the material before welding are reported in table 2 .

Table 2: Mechanical properties of the material Aluminum Alloy

\begin{tabular}{|c|c|c|c|c|}
\hline $\begin{array}{c}\text { Yield } \\
\text { Stress } \\
\sigma_{\mathbf{Y}}\end{array}$ & $\begin{array}{c}\text { Ultime } \\
\text { Tensile } \\
\text { Stress }\end{array}$ & $\begin{array}{c}\text { Rupture } \\
\text { Stress } \\
\boldsymbol{\sigma}_{\mathbf{R}}(\mathbf{M P a})\end{array}$ & $\begin{array}{c}\text { Elastic } \\
\text { Modulus } \\
\text { E (MPa) }\end{array}$ & $\begin{array}{c}\text { Strain } \\
\%\end{array}$ \\
\hline $\begin{array}{c}\sigma_{\text {UTS }}(\mathbf{M P a}) \\
110\end{array}$ & 160 & 127 & 60000 & 5.6 \\
\hline
\end{tabular}

The material is provided in the form of sheets of dimensions $1000 \times 1000 \times 2 \mathrm{~mm}$. Figure 2 shows welding process used is the friction stir welding (FSW) to joint two plates of aluminum alloy AA3003 with 250x60 mm and $2 \mathrm{~mm}$ thick, the welding is done in perpendicular direction to the direction of rolling..

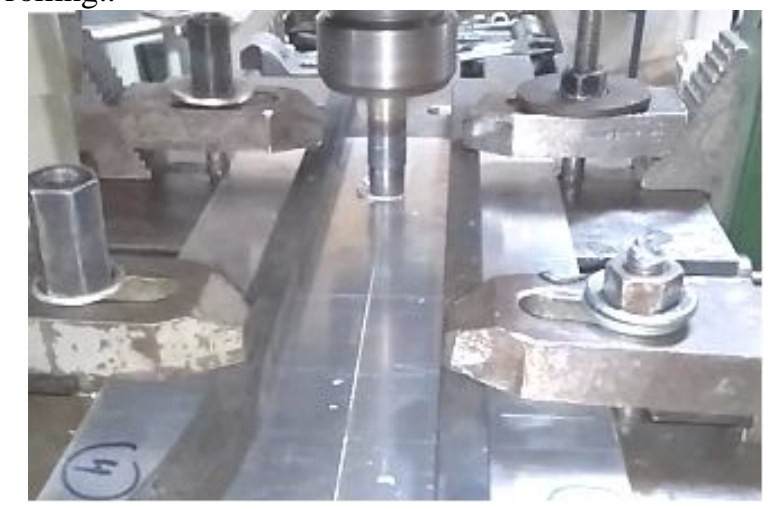

Figure 2: Friction Stir Welding Configuration.

The cutting operation of samples on the welded plates is represented in figure 3. A tensile test was carried out with a machine INSTRON tensile machine, controlled by the MTS software.

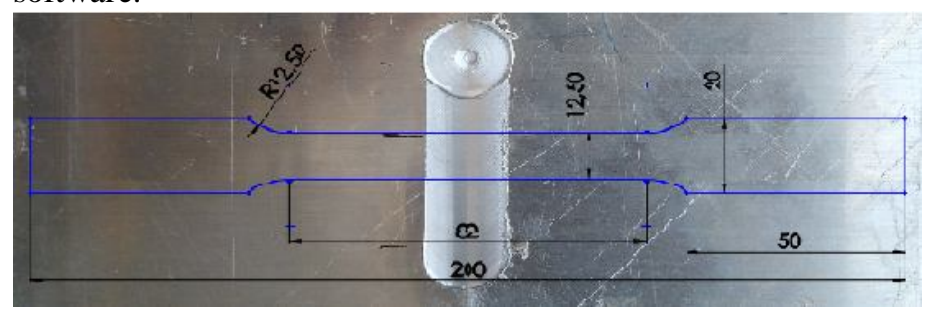

Figure 3: Cutting of samples on welded plates according to ASTM E8M8 (Dimensions in mm)

Figure 4 represent stress-strain curve of the welded specimen. Mechanical properties of the material welded are reported in table 3.

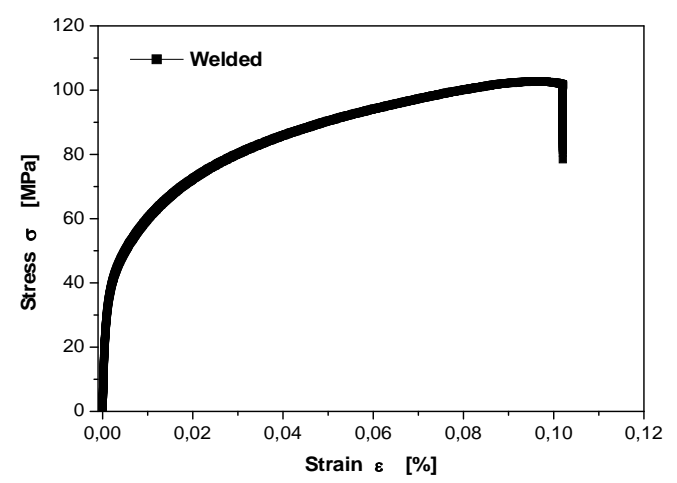

Figure 4: Stress-strain curve of the material welded[23].

Table 3: Mechanical properties of the welded material Aluminum

\begin{tabular}{|c|c|c|c|c|}
\hline Yield & Ultime & Rupture & Elastic & \\
Stress & Tensile & Stress & Modulus & Strain \\
$\sigma_{\mathbf{Y}}$ & Stress & $\sigma_{\mathbf{R}}(\mathbf{M P a})$ & E (MPa) & $\%$ \\
$(\mathbf{M P a})$ & $\sigma_{\text {UTS }}(\mathbf{M P a})$ & & & \\
\hline 38 & 102 & 78 & 48000 & 10.2 \\
\hline
\end{tabular}


The results obtained show that there is a decrease in the elastic limit and the resistance of the welded joint compared to the values obtained for the base metal. These reductions are due to the recrystallization phenomenon caused by the thermo mechanical effects combined with the rotational and translational movements of the pion during welding by FSW [24].These reductions are about $65 \%$ of the elastic limit and $38.5 \%$ of the tensile strength. These results are confirmed by for other types of aluminum [25], [26].

\subsection{Mixed Mode Tests}

The mixed mode tests are carried out on an INSTRON 8501 hydraulic machine with a capacity of $100 \mathrm{kN}$ controlled by the MTS software allowing data acquisition (load-displacement).Figure 7 shows the machine fitted with a loading device to testing CTS. The loading device based on Richard' principle [27] suitable CTS specimen was realized in our laboratory [28]. The geometry and dimensions of the CTS specimen and the loading device are shown respectively in figure 5 and 6 . CTS specimens with three different notch length were tested, $\mathrm{a} / \mathrm{W}=0.3 ; 0.5$ and 0.7 . The notch is obtained by water jet.

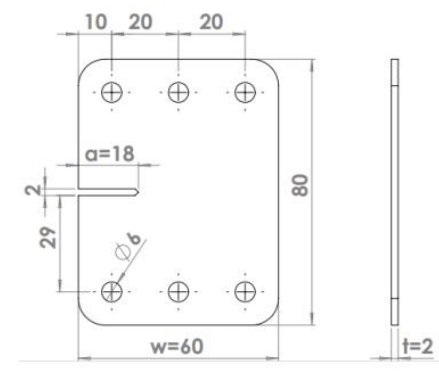

Figure 5: Geometry and dimensions of the CTS specimen
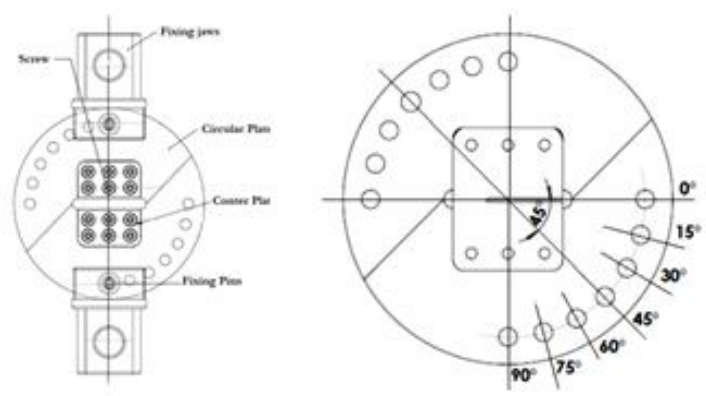

Figure 6:Loading device suitable for mixed mode [27].

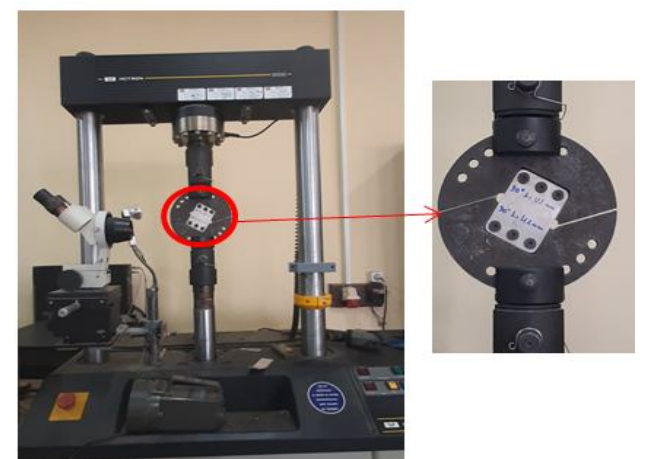

Figure 7: INSTRON 8501 testing machine and specimen mounting on the loading device.

The specimens were obtained by water jet cutting of an aluminum plate of dimensions $250 \times 120 \mathrm{~mm}$ and $2 \mathrm{~mm}$ thick for the non-welded specimens. Figure 8represents the cutting principle of non-welded CTS specimens. The welded specimens are obtained by water jet cutting of a plate resulting from the assembly of two plates of dimensions 250x60 mm welded perpendicularly in the direction of rolling by the friction stir welding process. Figure 9 shows the cutting principle of CTS welded specimens.Figure 10 shows the position of loading device for different loading angle during the application the tensile force. The loading angle $\alpha$ varies in steps of $15^{\circ}$, from 0 to $90^{\circ}$, thus the loading modes vary according to the value of this angle through a mode I (pure tensile) for loading angle $\alpha=0^{\circ}$ and at pure shear mode II for loading angle $\alpha=90^{\circ}$.For values of loading angle between $\alpha=15^{\circ}$ and $75^{\circ}$ the loading is in mixed mode.

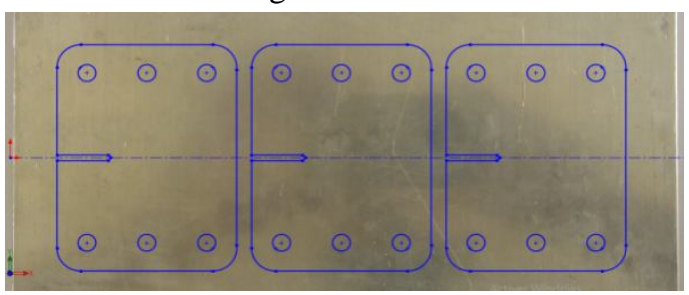

Figure 8: Cutting by water jet of non-welded specimen on plate of aluminum

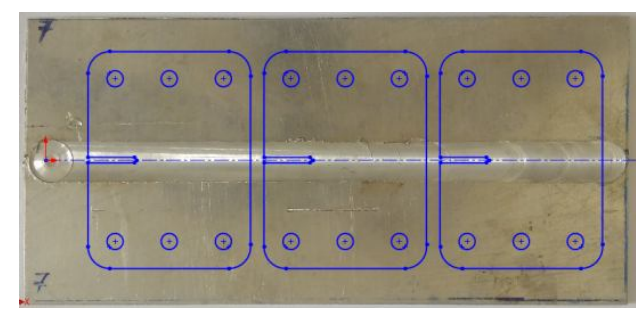

Figure 9: Cutting by water jet of welded specimen on plate of aluminum 


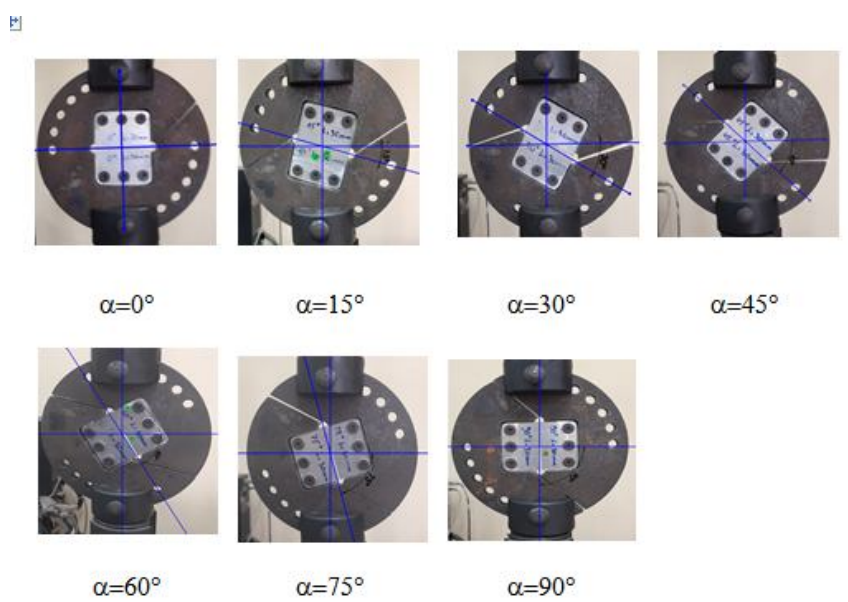

Figure 10: Position of loading device for different loading angle.

Table 4 summarizes the relation between the loading angle $\alpha$ and the loading modes.

Table 4:Relation between loading angle $\alpha$ and the modes of fracture.

\begin{tabular}{|c|c|c|c|}
\hline Mode & $\boldsymbol{\alpha}$, degrees & $\mathbf{K}_{\mathbf{I}}$ & $\mathbf{K}_{\text {II }}$ \\
\hline I & 0 & $\neq 0$ & 0 \\
\hline Mixed & $0<\alpha<90$ & $\neq 0$ & $\neq 0$ \\
\hline II & 90 & 0 & $\neq 0$ \\
\hline
\end{tabular}

\section{RESULTS AND DISCUSSIONS}

\subsection{Load-displacements curves}

The results of the mixed-mode fracture tests of non-welded and welded CTS specimens are presented under different loading angles and for the three normalized crack lengths (a / $\mathrm{W}=0.3 ; 0.5$ and 0.7 ) are represented respectively by figures 11 and 12 .

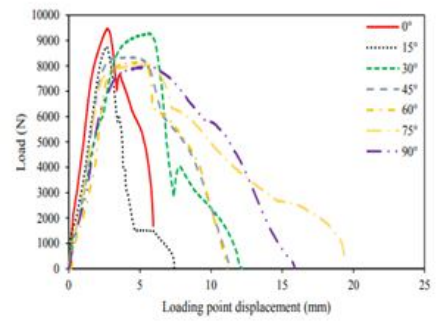

$\mathrm{a} / \mathrm{W}=0.3$ $\mathrm{a} / \mathrm{W}=0.5$
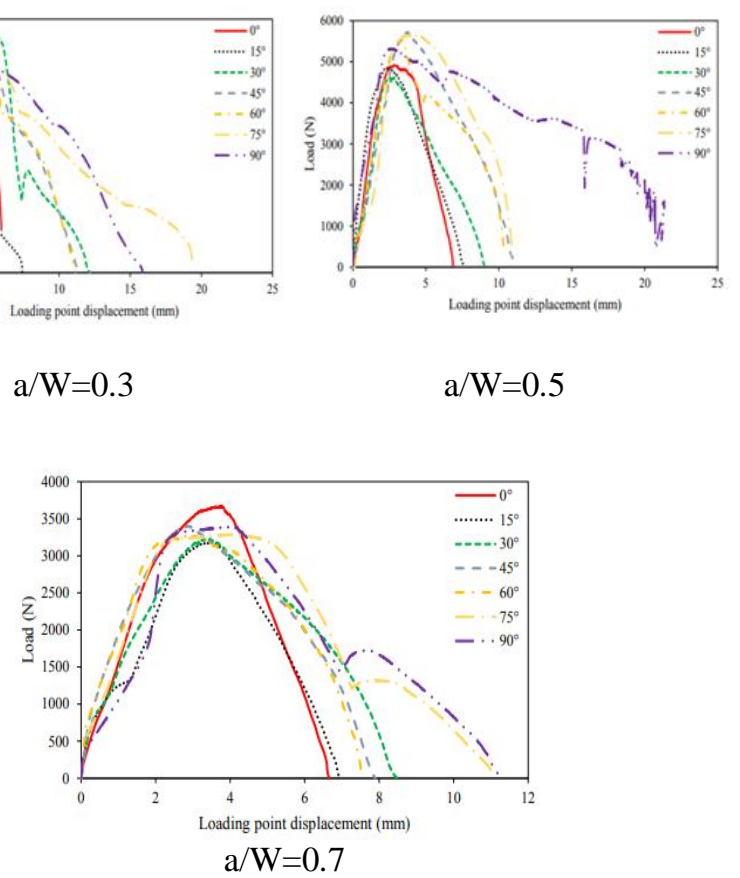

Figure 11: Curves Load-displacements by tests for non-welded specimens CTS.

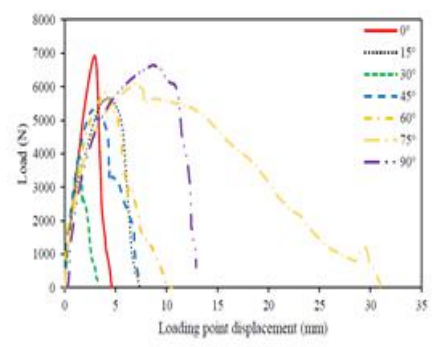

$\mathrm{a} / \mathrm{W}=0.3$

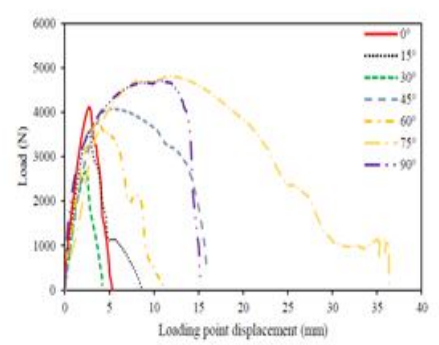

$\mathrm{a} / \mathrm{W}=0.5$

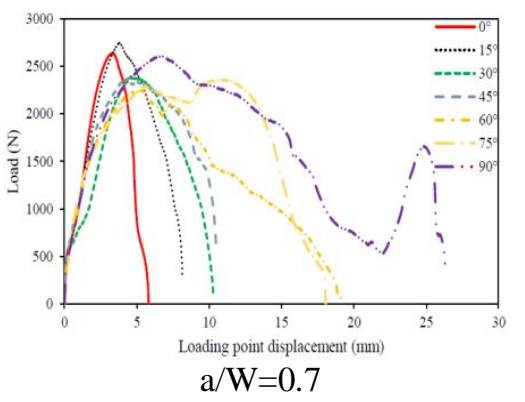

Figure 12: Curves Load-displacements by tests for welded specimens CTS.

The results obtained show that the load-displacement curves of CTS specimens with short crack lengths (a / W $=0.3$ ) present a maximum for an angle $\alpha=0^{\circ}$ (mode I) and the loads decrease gradually as the loading angles increase, implying that the mode II components increase. For CTS specimens with average notch lengths $(\mathrm{a} / \mathrm{W}=0.5)$, the load-displacementcurves follow the same trend as the curves obtained for short notches lengths, but with reduced deviations between the different curves.For CTS specimens with longer notches lengths (a / W = 0.7), the tendency of the load-displacement curve with the loading angle is opposite to those of Fig. 11 (a) and (b). That is to say that the curve of $\alpha=$ $90^{\circ}$ (loading in mode II) is at high, and the curves drop as the loading angles decrease (or mode I components increase).

The results obtained show that the load-displacement curves of the welded CTS specimens follow the same trends as for the non-welded specimens with values less important than those obtained previously.

\subsection{Evaluation of stress intensity factors $K_{\mathbf{I}} ; K_{\text {II }}$}

The stress factors intensity $\mathrm{K}_{I}$ and $\mathrm{K}_{I I}$ at tip of crack in Compact Tension Shear specimen are given by using equations (1) and (2) Richard [20].

$$
\begin{aligned}
\mathrm{K}_{I} & =\frac{P \sqrt{\pi a}}{W t} \cos \alpha f_{I}\left(\frac{a}{W}\right) \\
\mathrm{K}_{I I} & =\frac{P \sqrt{\pi a}}{W t} \sin \alpha f_{I I}\left(\frac{a}{W}\right)
\end{aligned}
$$

Where: $\mathrm{P}$ is the fracture load, a is notch length, $\mathrm{W}$ is the specimen width, $\mathrm{t}$ is the specimen thickness, the geometrical factors $f_{I}$ and $f_{I I}$ are obtained using finite element analysis and given by relations (3);(4): 
Hichem Mebarki et al., International Journal of Emerging Trends in Engineering Research, 9(9), September 2021, 1259 - 1265

$$
\begin{array}{r}
f_{I}\left(\frac{a}{W}\right)=2,32158-14,3677\left(\frac{a}{W}\right)+66,85752\left(\frac{a}{W}\right)^{2}- \\
117,66921\left(\frac{a}{W}\right)^{3}+89,72502\left(\frac{a}{W}\right)^{4}(3) \\
f_{I I}\left(\frac{a}{W}\right)=-0,05741+4,36076\left(\frac{a}{W}\right)-4,46168\left(\frac{a}{W}\right)^{2}+ \\
2,48807\left(\frac{a}{W}\right)^{3}(4)
\end{array}
$$

The variation of stress intensity factors $\mathrm{K}_{\mathrm{I}}$ and $\mathrm{K}_{\mathrm{II}}$ according the loading angles for CTS specimen non-welded and welded for three notches length $(\mathrm{a} / \mathrm{W}=0.3 ; 0.5$ and 0.7$)$ are shown in figures 13 and 14.

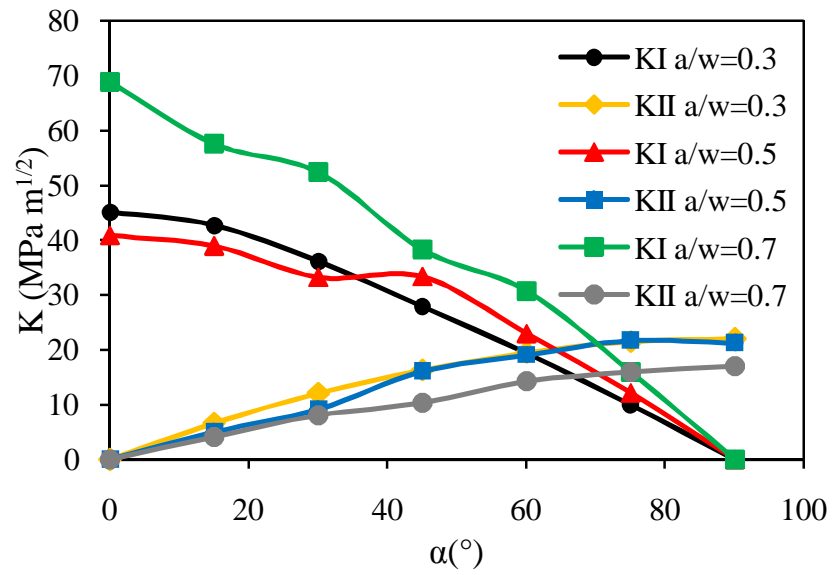

Figure 13: Variation of stress intensity factors $\mathrm{K}_{\mathrm{I}} ; \mathrm{K}_{\mathrm{II}}$ according the loading angle for CTS non-welded specimen.

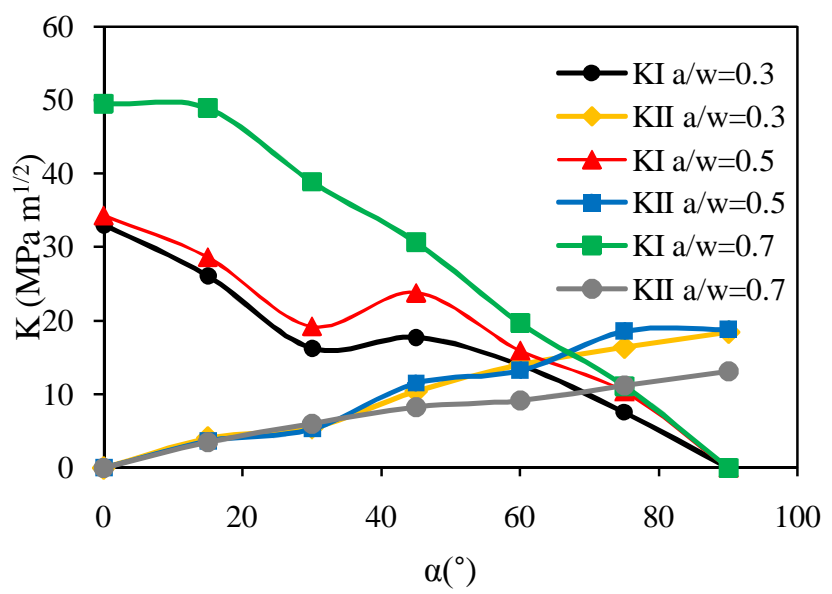

Figure 14: Variation of stress intensity factors $K_{I} ; K_{I I}$ according the loading angle for CTS welded specimen

The results show that the highest values of the stress intensity factors in mode I are obtained for the CTS specimen with long notches lengths $(\mathrm{a} / \mathrm{W}=0.7)$. The maximum is obtained for $\mathrm{a}$ loading angle $\alpha=0^{\circ}$ which represents mode I and the values decrease gradually as the loading angles increase, which implies the loading is in mixed mode, the values of stress intensity factors $\mathrm{K}_{\mathrm{II}}$ increase until a maximum is reached for loading angle $\alpha=90^{\circ}$ corresponding to mode II (pure shear). The tensile and shear stresses around the tip of the crack are equivalent for loading angle between $\alpha=60^{\circ}$ to $75^{\circ}$. Tensile stresses are dominant up to these values and beyond shear stresses become predominant.
For the CTS specimens with short and medium notches lengths $(\mathrm{a} / \mathrm{W}=0.3$ and $\mathrm{a} / \mathrm{W}=0.5)$, the same trend is observed for the values of the stress intensity factors $\mathrm{K}_{\mathrm{I}}$ in mode I. The factor stresses decrease when the loading angles increase until reaching the zero value for $\alpha=90^{\circ}$ corresponding to the loading in pure mode II.

The values of the stress intensity factor $\mathrm{K}_{\mathrm{II}}$ obtained for shorts notches are higher than those obtained for the test on CTS specimen with a long crack length $(\mathrm{a} / \mathrm{W}=0.7)$. This shows the length of the crack influences the variation of the $\mathrm{K}_{\mathrm{II}}$

\subsection{Fracture Cracks paths}

The fracture growth paths for the different specimens welded and non-welded for different loading angle and notch lengths are shown in figure 15 and 16.On the horizontal line, the samples are presented for the same loading angle and vertically the samples with the same notch length.For some samples, we could not take pictures because these test pieces were broken or have suffered deformations due to the device. For a loading angle $\alpha=0$ (where the notch is perpendicular to the loading) corresponding to a loading in mode I, the growth of the crack undergoes a deviation compared to the origin of the notch. The angles of deviation are respectively $40^{\circ}, 5^{\circ}$ and $11^{\circ}$ for a $/ \mathrm{W}=0.3 ; 0.5$ and 0.7. For a short notch length the deviation is very important for non-welded specimens.

For the same loading angle $\alpha=0$, the growth of the cracks for

\begin{tabular}{|c|c|c|c|}
\hline & $\mathrm{a} / \mathrm{W}=0.3$ & $\mathrm{a} / \mathrm{W}=0.5$ & $\mathrm{a} / \mathrm{W}=0.7$ \\
\hline $0^{\circ}$ & & & \\
\hline $45^{\circ}$ & & & \\
\hline $60^{\circ}$ & & & \\
\hline $90^{\circ}$ & & & \\
\hline & & & \\
\hline & & & \\
\hline
\end{tabular}
the welded specimens, does not undergo any deviation and the propagation takes place in the axis of the notch except for a / $\mathrm{W}=0.7$ where the crack deviates by $39^{\circ}$.

Figure 15: Fracture cracks paths for non-welded specimen 


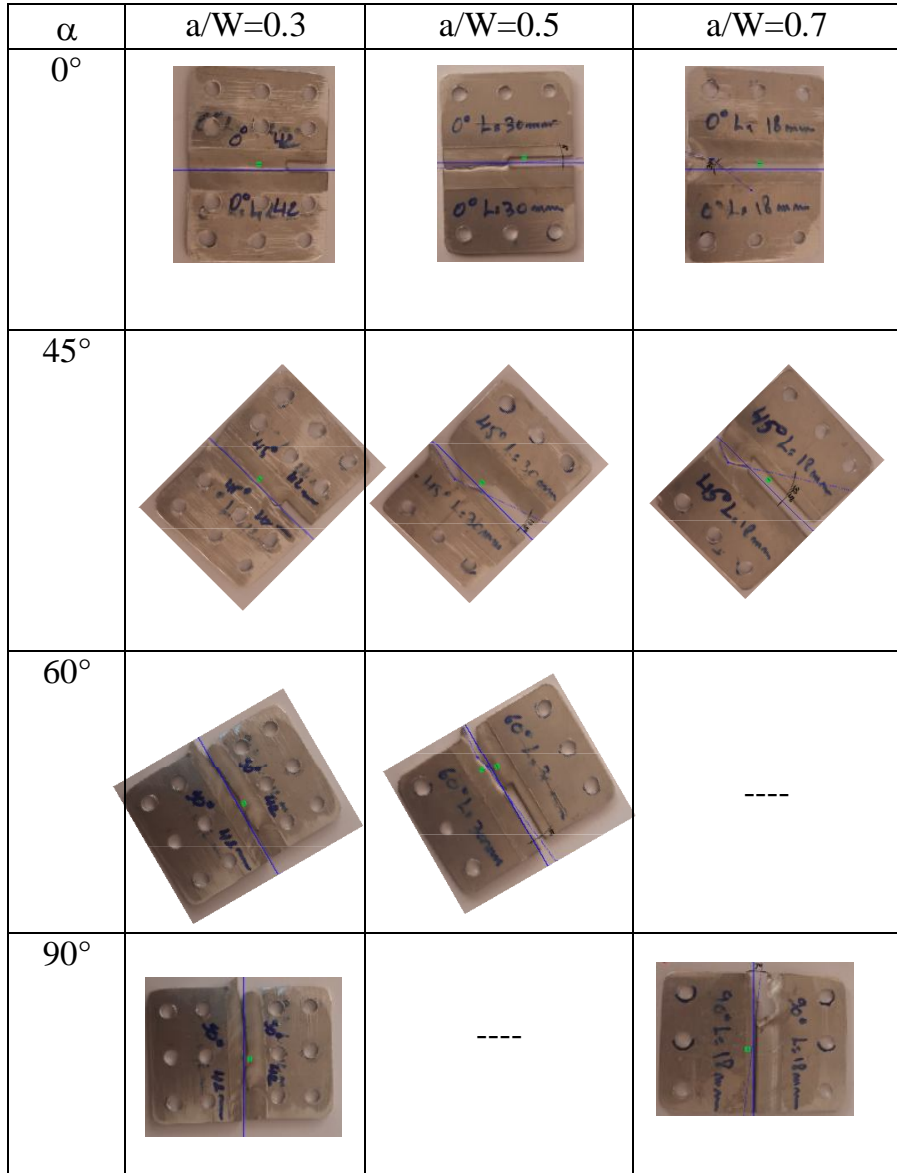

Figure 16: Fracture cracks paths for welded specimen

For angles 45 and 60 corresponding to a mixed loading in mode I and II, the propagation paths depend on the length of the notch. For the non-welded specimens the deviations from the original direction are $19^{\circ} ; 21^{\circ}$ and $13^{\circ}$ respectively for the non-dimensional lengths a $/ \mathrm{W}=0.3 ; 0.5$ and 0.7 . For welded specimens, there is no deviation for a / $\mathrm{W}=0.3$ while the propagation deviates by $4^{\circ}$ and $11^{\circ}$ respectively for the lengths a / $\mathrm{W}=0.5$ and 0.7 .

For an angle $\mathrm{a}=90$ corresponding to pure shear, one observes for the non-welded test pieces deviations of $4^{\circ}$ and $15^{\circ}$ for a / $\mathrm{W}=0.3$ and 0.7 .

On the other hand, for welded specimens, there is no deviation for $\mathrm{a} / \mathrm{W}=0.3$ and a deviation of $7^{\circ}$ for $\mathrm{a} / \mathrm{W}=0.7$.

\section{CONCLUSION}

The present experimental study investigates the influence of crack length ratio $\mathrm{a} / \mathrm{w}$ and loading angles on fracture parameters in mode I and II of CTS welded specimens. The CTS specimens in 3003 Al-alloy are welded by FSW welding process. The obtained results show that:

- Mechanical properties of welded specimens are decreased comparatively to the base metal.

- Two mode loading are applied and reveal that the highest values of the stress intensity factors in mode I are obtained for the CTS specimen with long notches lengths $(\mathrm{a} / \mathrm{W}=0.7)$.
- The stress intensity factor KI and KII decrease in decreasing of loading angle for welded and non-welded specimens.

- The crack paths angles depend essentially on the angles of applied load and notch length ratio a/w for non-welded specimens.

- In welded specimens, the crack paths angles are decrease or neglected in functions of notch length

\section{REFERENCES}

1. R.S. Mirsha, and Z. Y. Ma.Friction stirs welding and processing,Materials Science and Engineering $R$ : Reports 50, pp. 1-78,2005. DOI: 10:1016/J.mser.2005.07.001

2. C.Q. Li, G.Fu, W. Yang, S. Yang.J-Integral solution for elastic fracture toughness for plates with inclined cracks under biaxial loading, Journal of Engineering Mechanics, 144(6), 2018. DOI: 101061/ (ASCE) EM.1943-7889.0001444.

3. H.Aydin,A. Bayram, A. Uuz, and K. S. Akay. Tensile properties of friction stir welded joints of 2024 aluminum alloys in different heat-treated-state,Materials and Design, 30:2211 2221,

2009.https://doi.org/10.1016/j.matdes.2008.08.034.

4. D. Booth and I. Sinclair.Fatigue of friction stir welded 2024-T351 Aluminum Alloy, Materials Science Forum, 396-402:1671-1676,2002.

https://doi.org/10.4028/www.scientific.net/msf.396-402 .1671

5. P. Cavaliere, R. Nobile, F. Panella, and A. Squllace.Mechanical and microstructural behavior of 2024-7075 aluminum alloy sheets joined by friction welding, International Journal of Machine Tools and Manufacture, 46:588 - 594,2006b.

DOI: $10.1016 /$ j.ijmachtools.2005.07.010

6. D.Fersini, and A.Pirondi.Fatigue behaviour of Al2024-T3 friction stir welded lap joints, Engineering Fracture Mechanics, 74:468-480, 2007. DOI:10.1016/j.engfracmech2006.07.010

7. C. Genevois, A. Deschamps, and P. Vacher.Comparative study on local and global mechanical properties of 2024 T351, 2024 T6 and 52510 friction stir welds,Materials Science and Engineering, A415:162-170,2005b. DOI:10.1016/jmsea.2005.09.032.

8. S. Liu, and Y. J. Chao.Determination of global mechanical response of friction stir welded plates using local constitutive properties,Modelling and Simulation in Materials Science and Engineering, 13:1-15, 2004. DOI:10.1088/0965-0393/13/1/001

9. B.E.Amstutz, D.S. Dawicke, and J.C. Newman Jr.An experimental study of COD formode I/II stable crack growth in thin 2024-T3 aluminum specimen, $A S T M$ STP1256 on Fracture Mechanics; 26: 256-271,1995.

10. B.E.Amstutz, M.A. Sutton, D.S.Dawicke, and M.L.Boone. Effects of mixed mode I/IIloading and grainorientation on crack initiation and stable tearing 
Hichem Mebarki et al., International Journal of Emerging Trends in Engineering Research, 9(9), September 2021, 1259 - 1265

in 2024-T3 aluminum, ASTM STP 1256 on Fatigue and Fracture Mechanics, 27: 105-126,1997. https://doi.org/10.1520/STP16231S

11. K.Tohgo, and H.Ishii.Elastic-plastic fracture toughness test under mixed mode I-II loading, Engng.Fract. Mech., 41; 529-540, 1992.DOI:10.1016/0013-7944(92)90299-T

12. S.Aoki, K. Kishimoto, T. Yoshida, M. Sakata, A. Richard. Elastic-plastic fracture behavior of an aluminum alloy under mixed mode loading, $J$ MechPhys Solids, 38; 195-213, 1990. DOI:10.1016/0022-5096(90)90034-2

13. M.C. Sutton, X. Deng, F. Ma, JC. Newman Jr, M. James. Development and application of a crack tip opening displacement-based mixed mode fracture criterion, Int. J. Struct. Solids, 37: 3591- 3618, 2000. DOI: 10.1016/S0020-7683(99)00055-4

14. Richard, H.A. (1981). A new compact shear specimen, International Journal of Fracture, 17, pp. R105-R107.

15. S.B.Biner.Fatigue Crack Growth Studies Under Mixed-mode Loading, International Journal of Fatigue,23,pp. S259-S263, 2001. DOI:10.1016/S0142-1123(01)00146-3

16. L.P.Borrego, F.V.Antunes, J.M. Ferreira, and J.D. Costa. (2004). Mixed-mode fatigue crack growth andclosure in aluminum alloys, in Proc. 7th ICBMFF- Seventh International Conference on Biaxial/Multiaxial Fatigue Fracture, Berlin, Germany, pp.1483-488,2004.

17. R.Rikards, F.G. Buchholz,H. Wang A.K.Bledzki,A. Korjakin.Investigation of mixed Mode I/II Interlaminar Fracture Toughness of Laminated Composites by Using a CTS Type Specimen, Engineering Fracture Mechanics, 51,pp. 325-342,1998. DOI:10.1016/S0013-7944(98)00068-X

18. K.S. Madhusudhana, and R.Narasimhan. Experimental and numerical investigations of mixed mode crack growth resistance of a ductile adhesive joint, Engineering Fracture Mechanics, 69, pp. 865-883, 2002. DOI:10.1016/S0013-7944(01)00110-2

19. A.Pirondi, and G. Nicoletto.Mixed Mode I/II Fracture Toughness of Bonded Joints,International Journal of Adhesion and Adhesives, 22, pp.109-117, 2002. DOI: 10.1016/S0143-7496(01)00042-2.

20. H.A. Richard. Some theoretical and Experimental Aspects of Mixed Mode Fracture, Advances Fracture Fracture Research, Vol. 5, pp. 3337-3344, 1986.ISBN 0080293093.

21. F. V. Antunes, R. Branco, J. M. Ferreira, L.P. Borrego.Stress Intensity Factor Solutions for CTS Mixed Mode Specimen, FratturaIntegritàStrutturale, 48, 676-69, 2019.DOI:10.3221/IGF-ESIS.48.64

22. I. Al Emran.Stress IntensityFactors of Cracks in Solid Cysislindrical Bars using ANSYS Finite Element Analy. International Journal Emerging of Trends in Engineering Research, Vol. 8, n4,pp.1395-1404, 2020.https://doi.org/10.30534/ijeter/2020/10387202 0

23. I. Chekalil, A. Miloudi, M.P. Planche, A. Ghazi. Prediction of mechanical behavior of friction stir welding joints of AA3003 aluminum alloy, FracturaedIntegritàStrutturale, Vol. 54 pp. 153-168, 2020.

24. C. Genevois.Genesis of microstructures during friction stir welding of aluminum alloys of the 2000 and 5000 series and resulting mechanical behavior (in French) ; PhD Thesis, INP Grenoble, France ,2004.

25. V. Balasubramanian. Relationship between base metal properties and friction stir welding process parameters,Materials Science and Engineering: A, 480:178, 2008. DOI: 10.1016/j.msea.2007.07.048

26. K.Elangovan, and V. Balasubramanian.Influence of pin prole and rotational speed of the tool on the formation of friction stir processing zone in AA2219 aluminumalloy,Materials Science and Engineering: A, 459:718, 2007.https://doi.org/10.1080/10426910701860723

27. H.A. Richard and K.Benitz. A loading device for the creation of mixed mode in fracture mechanics, International Journal of Fracture, 22, pp. R55-R58.1983. https://doi.org/10.1007/BF00942726.

28. S. Amrane.Design and Realization of a device for the mechanical characterization of materials in combined loading,Master thesis, department of mechanical engineering, Universityof SidiBel Abbes, Algeria, 2018. 